\title{
Penerapan Datamining pada Data Gempa Bumi Terhadap Potensi Tsunami di Indonesia
}

\author{
Dito Putro Utomo ${ }^{1}$, Bister Purba ${ }^{2}$ \\ Program Studi Teknik Informatika, STMIK Budi Darma, Medan, Indonesia \\ Jln. Sisingamangaraja No. 338 Medan, Indonesia \\ ditoputro12@gmail.com, bisterpurba91@gmail.com
}

\begin{abstract}
Indonesia is a maritime country that is located on 3 plates of the world or commonly called the Ring of Fire which causes frequent earthquakes. The earthquake is the biggest threat faced by the potential of the tsunami in it which can cause damage and even cause casualties. Data mining can explore pre-existing earthquake data and draw a pattern or conclusion from a database. The Naïve Bayes Classifier (NBC) algorithm is part of the data mining classification technique that is used to estimate or predict the chances of a possibility occurring. Based on the results and discussion, conclusions can be drawn by applying the Naïve Bayes Classifier (NBC) algorithm on earthquake data to potential tsunamis in Indonesia to find out the possible effects of earthquakes. With the testing data used the effect produced is the Potential Tsunami.
\end{abstract}

Keywords :Data Mining, Naïve Bayes Classifier, Tsunami, Earthquake

Abstrak- Indonesia merupakan negara maritime yang terletak pada 3 lempengan dunia atau biasa disebut dengan Ring of Fire (Cincin Api Pasifik) yang menyebabkan sering terjadi potensi gempa bumi. Gempa bumi merupakan ancaman terbesar dihadapai dengan potensi tsunami didalamnya yang dapat menyebabkan kerusakan bahkan menyebabkan korban jiwa.Dengan data mining dapat mengekplorasi data - data gempa bumi yang sudah ada sebelumnya dan menarik sebuah pola atau kesimpulan dari sebuah basis data.Algoritma Naïve Bayes Classifier (NBC) merupakan bagian dari teknik klasifikasi data mining yang digunakan untuk memperkirakan atau memprediksi peluang kemungkinan yang terjadi.Berdasarkan hasil dan pembahasan dapat ditarik kesimpulan bahwasaannya dengan menerapkan algoritma Naïve Bayes Classifier (NBC) pada data gempa bumi terhadap potensi tsunami di Indonesia bisa mengetahui kemungkinan efek yang diakibatkan pada gempa bumi.Dengan data testing yang digunakan efek dihasilkan adalah Potensi Tsunami.

Kata Kunci :Data Mining, Naïve Bayes Classifier, Tsunami, Gempa Bumi

\section{PENDAHULUAN}

Indonesia sebuah negara maritim dimana luas lautan lebih besar dari luas daratan, Indonesia sebuah negara berada dikawasan Asia Tenggara yang berada pada garis khatulistiwa, secara geografis Indonesia terletak diantara diantara 2 benua yaitu Asia dan Australia juga 2 buah samudera yakni Samudera Hindia dan Samudera Pasifik. Selain geografis, Indonesia terletak secara astronomis di $6^{\circ} \mathrm{LU}$ (Lintan Utara) - $11^{\circ} \mathrm{LS}$ (Lintang Selatan) dan $95^{\circ} \mathrm{BT}$ (Bujur Timur) - $141^{\circ} \mathrm{BT}$ (Bujur Timur). Berdasarkan letak astronomis tersebut meletakan Indonesia berada pada 3 lempengan utama dunia yaitu Lempengan Eurasia, Lempengan Indoaustralia dan Lempengan Pasifik posisi letak Indoneisa ini dikenal dengan wilayah Ring of Fire (Cincin Api Pasifik) terbentang sejauh 40.000 Km yang menyebabkan sangat sering 
terjadi potensi gempa bumi di wilayah Indonesia serta letusan - letusan gunung berapi diwilayah cekungan Samudra Pasifik. Gempa bumi merupakan ketakutan terbesar bagi penduduk Indoneisa, dalam setahun rata - rata terjadi gempa bumi sebanyak 6000 kali dengan segala bentuk dampak yang diakibatkan. Salah satu dampak akibat yang ditimbulkan oleh gempa bumi tersebut adalah Tsunami, sering kali Tsunami menyebabkan kerusakan diwilayah Indonesia bahkan sampai menyebabkan korban jiwa sebagai contoh Tsunami akibat gempa bumi di Aceh pada tahun 2004, Tsunami yang diakibatkan gempa bumi di Kepulauan Mentawai pada tahun 2010 dan lain sebagainya. Sehingga perlu perhatian serta penangan khusus terhadap dampak dari gempa bumi seperti tsunami tersebut dengan mengetahui dampak dan akibat yang ditimbulkan ketika terjadi gempa bumi dengan memanfaatkan data - data yang sudah terekam terlebih dahulu.

Data mining diartikan merupakan sekumpulan proses yang berguna mengeksplorasi dan mencari nilai berupa informasi juga relasi - relasi kompleks yang selama ini tersimpan dari suatu basis data. Dengan melakukan penggalian pola informasi terhadap data yang berguna sebagai memanipulasi data menjadi sebuah informasi baru serta lebih bermanfaat yang didapatkan melalui cara mengekstraksi juga mengetahui pola - pola yang berharga atau menarik yang didapatkan dari data didalam basis data. Data mining digunakan untuk pengelolaan data yang besar serta membantu proses penyimanan data transaksi dan memproses data warehousing agar kiranya bisa mendapatkan informasi yang diperlukan bagi penggunanya. Dengan data mining kiranya dapat mengetahui dampak atau akibat yang ditimbulkan dari gempa bumi yang terjadi di Indoneisa berdasarkan dari data sampel atau data gempa bumi yang sudah terjadi sebelumnya. Salah satu cara pemenfaatan data mining melalui salah satu teknik data mining yaitu klasifikasi, dengan teknik klasifikasi akan mengelompokan akibat yang ditimbulkan oleh gempa bumi berdasarkan dengan atribut - atribut tertentu. Berdasarkan penelitian-penelitian yang sudah dilaksanakan sebelumnya banyak menggunakan teknik data mining untuk mencari informasi baru yang dapat dimanfaatkan dari data sampel yang sudah ada.Naïve Bayes Classifier merupakan algoritma pada data mining yang merupakan bagian dari pada teknik klasifikasi data mining, Nä̈ve Bayes Classifier merupakan algoritma yang berlandaskan Teorema Bayes menggunakan teknik probabilitas dan statistik untuk meperkirakan ataupun memprediksi peluang yang akan terjadi berdasarkan dengan pengalaman sebelumnya.

Berdasarkan penelitian terdahulu oleh Efori Buulolo mengatakan "Algoritma data mining dapat memprediksi dampak gempa bumi berdasarkan data seismik yang pernah terjadi dan dampak gempa dipengaruhi oleh beberapa karakteristik atau kondisi gempa yang terjadi" [1]. Selain itu, penelitian lainnya yang telah dilakukan oleh Sandi Fajar Rodiyansyah mengatakan "Algoritma Naïve Bayes Classifier memiliki kinerja yang cukup tinggi untuk proses klasifikasi dengan melakukan pengujian sebanyak 13106 terhadap data sampel menghasilkan nilai akurasi terkecil sebesar 78\% dan nilai akurasi terbesar 91,60\%" [2].

\section{METODOLOGI PENELITIAN}


Metodologi penelitian berguna sebagai fungsi signifikan untuk mendapatkan informasi/data yang dibutuhkan didalam menyelesaikan berbagai macam masalah dan bermanfaat memberikan sebuah solusi atas masalah yang ada. Akan lebih bagus jika metodologi penelitian disesuaikan dengan subjek/objek penelitian. Metodologi yang tidak sesuai didalam melaksanakan penelitian akan menyebabkan kerancuan dimana pada akhirnya menghasilkan penelitian yang tidak valid dan tidak bisa dipertanggung jawabkan. Tahapan metode penelitian merupakan alur langkah yang akan dikerjakan selama melakukan penelitian, dimana dimulai pada tahap formulasi masalah hingga sampai pada kesimpulan atau hasil dari penelitian. Atau dapat dilihat pada gambar dibawah ini :

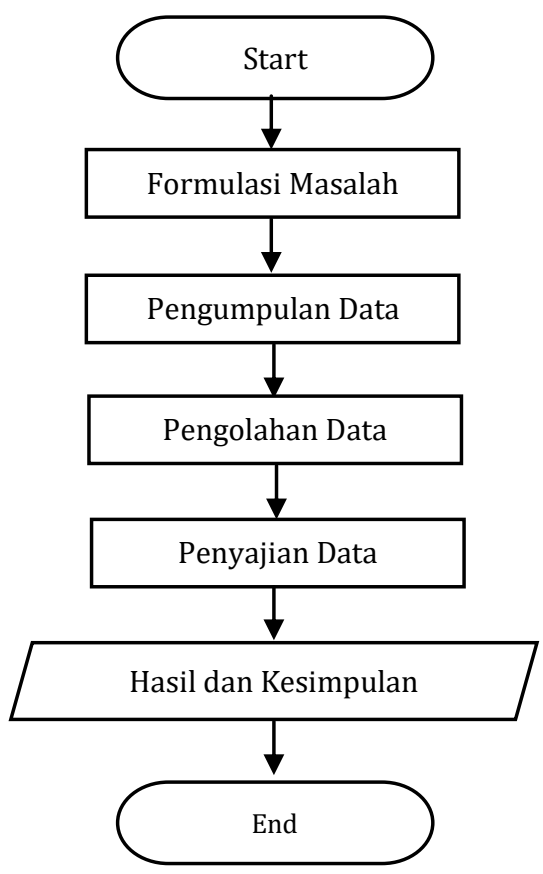

Gambar 1. Metodologi Penelitian

\subsection{Data Mining}

Data mining adalah bagaimana mencari data yang tersedia untuk menciptakan sebuah model, lalumemanfaatkan model tersebut untuk mengenali pola data lain yang tidak tersediadidalam basis data yang tersimpan. Dalam data mining pengelompokan data dapat juga dilakukan untuk mengetahui pola secara universal dari data yang tersedia agar dilakukan langkah tindak lanjut lainnya yang berguna sebagai pendukung kegiatan dan tujuan akhir tertentu" [3].

\subsection{AlgoritmaNaïve Bayes Classifier (NBC)}

Merupakan algoritma klasifikasi statistik dimana digunakan untuk melakukan prediksi secara probabilitas (kemungkinan) pada anggota suatu class.Dasar dari NBC merupakan teorema bayes dimana mempunyai kemampuan untuk melakukan klasifikasi, NBC hamper sama dengan pohon keputusan serta jaringan syaraf. NBCmemiliki tingkatan akurasi yang tinggi jika digunakan pada 
basis data yang memiliki data yang besar [6].Teorema Bayes memiliki persamaan umum :

$$
\begin{aligned}
& \mathrm{P}(\mathrm{H} \mid \mathrm{X})=\frac{P(X \mid H) P(H)}{P(X)} \\
& \mathrm{X} \quad=\text { Data dengan class yang belum diketahui } \\
& \mathrm{H} \quad=\text { Hipotesis data X merupakan suatu class spesifik } \\
& \mathrm{P}(\mathrm{H} \mid \mathrm{X})=\text { Probabilitas hipotesis } \mathrm{H} \text { berdasarkan kondisi } \mathrm{x} \text { (posteriori prob.) } \\
& \mathrm{P}(\mathrm{H})=\text { Probabilitas hipotesis } \mathrm{H} \text { (prior prob.) } \\
& \mathrm{P}(\mathrm{X} \mid \mathrm{H})=\text { Probabilitas } \mathrm{X} \text { berdasarkan kondisi tersebut } \\
& \mathrm{P}(\mathrm{X}) \quad=\text { Probabilitas dari } \mathrm{X}
\end{aligned}
$$

\subsection{Gempa Bumi}

Gempa bumi merupakan sebuah peristiwa berguncangnya bumi dikarenakan pergerakan/pergeseran lapisan batuan yang berada di kulit bumi yang tiba-tiba dikarenakan pergerakan lempengan tektonik.Gempa bumi diakibatkan aktivitas dari pegerakan lempeng tektonik dapat disebut dengan gempa bumi tektonik. Selain itu juga gempa bumi dapat terjadi dikarenakan aktifitas dari gunung berapi atau bisa disebut dengan gempa bumi vulkanik. Pergerakan tiba-tiba dari lapisan batuan di dalam bumi menghasilkan energi yang dipancarkanmerupakan gelombang gempat bumi ataupun gelombang sismik [7].

\subsection{Tsunami}

Tsunami merupakan pergerakan air diakibatkan dari permukaan laut secara vertikal. Perubahan dari permukaan lait ini dapat dikarenakan gempa bumi yang berasal dari bawah laut, letusan gunung berapi bawah laut, longsor bawah laut, atau hantaman meteor dilaut, gelombang tsunami bisa menjalar di segala arah. Tenaga yang terkandung didalam gelombang tsunami berdasarkan dengan ketinggian dan laju gelombang tsunami tersebut. Di dalam laut, kecepatan gelombang tsunami hingga 500-1000 Km/jam sama seperti kecepatan pesawat terbang.

\section{HASIL DAN PEMBAHASAN}

\subsection{Analisa Masalah}

Indonesia merupakan sebuah negara maritim yang dimana luas lautan lebih besar dari daratan, Indonesia merupakan sebuah negara yang terletak pada garis khatulistiwa yang meletakan indoneisa pada 3 lempengan utama dunia atau letak ini dikenal dengan wilayah Ring Of Fire (Cincin Api Pasifik) terbentang sejauh $40.000 \mathrm{Km}$ yang menyebabkan sering terjadinya potensi gempa bumi diwilayah indonesia serta letusan - letusan gunung berapi diwilayah cekungan samudera pasifik. Gempa bumi merupakan sebuah ketakutan bagi penduduk Indonesia, salah satu dampak akibat yang ditimbulkan oleh gempa bumi tersebut adalah tsunami.Sering kali tsunami menyebabkan kerusakan di Indonesia bahkan sampai menyebabkan hilangnya korban jiwa.Sehingga perlu perhatian serta penanganan khusus terhadap dampak dari gempat bumi seperti tsunami tersebut dengan mengetahui dampak dan akibat yang ditimbulkan ketika terjadinya gempa bumi tersebut. 


\subsection{Pengumpulan Data}

Pengumpulan data menggunakan studi literatur yang dimana teknik pengumpulan data berdasarkan sumber - sumber yang sudah ada.Untuk pengumpulan data disini berdasrkan data sampel yang disajikan melalui website BMKG. Pada pengumpulan data atribut yang didapatkan terdapat 6 data yaitu, Daerah Gempa Bumi, Pusat Gempa, Jarak Dari Pantai, Kedalaman, Skala (Kekuatan Gempa) dan juga dampak yang diakibatkan oleh gempa.

Tabel 1. Data Gempa Bumi

\begin{tabular}{|l|l|l|l|l|l|l|}
\hline No & $\begin{array}{l}\text { Daerah Gempa } \\
\text { Bumi }\end{array}$ & Pusat Gempa & $\begin{array}{l}\text { Jarak Dari } \\
\text { Pantai } \\
\mathbf{( K m )}\end{array}$ & $\begin{array}{l}\text { Kedalaman } \\
\mathbf{( K m )}\end{array}$ & Skala & Efek \\
\hline 1 & Donggala & Laut & 25 & 11 & 7.4 & Tsunami \\
\hline 2 & Donggala & Laut & 27 & 10 & 7.7 & Tsunami \\
\hline 3 & Lombok Timur & Laut & 18 & 15 & 7 & Tsunami \\
\hline 4 & Tasikmalaya & Laut & 11 & 107 & 6.9 & Potensi Tsunami \\
\hline 5 & Tasikmalaya & Laut & 43 & 105 & 7.3 & Tsunami \\
\hline 6 & Kep. Sangihe & Laut & 206 & 43 & 7.3 & Potensi Tsunami \\
\hline 7 & Kep. Mentawai & Laut & 636 & 10 & 7.8 & Potensi Tsunami \\
\hline 8 & Bitung & Laut & 155 & 48 & 7.3 & Potensi Tsunami \\
\hline 9 & Sumba & Laut & 103 & 10 & 6.7 & Tidak Berpotensi \\
\hline 10 & Seram Timur & Laut & 73 & 10 & 5.7 & Tidak Berpotensi \\
\hline 11 & Manokwari & Laut & 55 & 26 & 6.1 & Tidak Berpotensi \\
\hline 12 & Manado & Laut & 38 & 97 & 5.6 & Tidak Berpotensi \\
\hline 13 & Bali & Laut & 61 & 10 & 6.4 & Tidak Berpotensi \\
\hline 14 & Kep. Mentawai & Laut & 105 & 26 & 6.1 & Tidak Berpotensi \\
\hline 15 & Sumba Barat & Laut & 103 & 10 & 6.2 & Tidak Berpotensi \\
\hline
\end{tabular}

Dimana :

a. Jarak dari pantai merupakan jarak pusat gempat yang terjadi ke bibir pantai atau daratan yang paling dekat.Jarak dari pantai terdapat 3 kategori dimulai dari Dekat, Sedang dan jauh.

Tabel 2. Kategori Jarak Dari Pantai

\begin{tabular}{|l|l|}
\hline Jarak & PreProsesing \\
\hline $0-25 \mathrm{Km}$ & Dekat \\
\hline $26-100 \mathrm{Km}$ & Sedang \\
\hline$>100 \mathrm{Km}$ & Jauh \\
\hline
\end{tabular}

b. Kedalaman merupakan kedalaman dari pusat gempa yang terjadi hingga ke permukaan air pada lai. Kedalaman terdapat 2 kategori yaitu, Dalam dan Sangat Dalam

Tabel 3.Kategori Kedalaman

\begin{tabular}{|l|l|}
\hline Kedalaman & PreProsesing \\
\hline$<=15 \mathrm{Km}$ & Dalam \\
\hline$>15 \mathrm{Km}$ & Sangat Dalam \\
\hline
\end{tabular}

c. Skala 
Skala merupakan Skala Ritcher atau kekuatan yang terjadi pada gempa bumi, yang tercatat BMKG. Skala terdapat 3 kategori yaitu, Rendah, Sedang dan Tinggi

Tabel 4. Kategori Skala

\begin{tabular}{|l|l|}
\hline Skala & PreProsesing \\
\hline$<5,0$ & Rendah \\
\hline $5,1-7,0$ & Sedang \\
\hline$>7,0$ & Tinggi \\
\hline
\end{tabular}

\subsection{Pembahasan}

Berdasarkan dari data yang sudah dikumpulkan dan juga tahapan preprosesing atau pengelompokan data. Sehingga dapat dibuat data baru yang sudah melalui tahapan Preprosessing tersebut, dimana data tersebut yang akan digunakan pada tahap pemrosesan dan ditarik kesimpulannya.

Tabel 5. Data Hasil Preprosesing

\begin{tabular}{|l|l|l|l|l|}
\hline No & Jarak Dari Pantai (Km) & Kedalaman (Km) & Skala & Efek \\
\hline 1 & Dekat & Dalam & Tinggi & Tsunami \\
\hline 2 & Sedang & Dalam & Tinggi & Tsunami \\
\hline 3 & Dekat & Dalam & Sedang & Tsunami \\
\hline 4 & Dekat & Sangat Dalam & Sedang & Potensi Tsunami \\
\hline 5 & Sedang & Sangat Dalam & Tinggi & Tsunami \\
\hline 6 & Jauh & Sangat Dalam & Tinggi & Potensi Tsunami \\
\hline 7 & Jauh & Dalam & Tinggi & Potensi Tsunami \\
\hline 8 & Jauh & Sangat Dalam & Tinggi & Potensi Tsunami \\
\hline 9 & Jauh & Dalam & Sedang & Tidak Berpotensi \\
\hline 10 & Sedang & Dalam & Sedang & Tidak Berpotensi \\
\hline 11 & Sedang & Sangat Dalam & Sedang & Tidak Berpotensi \\
\hline 12 & Sedang & Sangat Dalam & Sedang & Tidak Berpotensi \\
\hline 13 & Sedang & Dalam & Sedang & Tidak Berpotensi \\
\hline 14 & Jauh & Sangat Dalam & Sedang & Tidak Berpotensi \\
\hline 15 & Jauh & Dalam & Sedang & Tidak Berpotensi \\
\hline
\end{tabular}

Untuk menguji data yang sudah didapatkan, diperlukan data testing untuk melihat dampak yang diakibatkan oleh gempa tersebut.

Tabel 6. Data Testing

\begin{tabular}{|l|l|l|l|l|}
\hline No & Jarak Dari Pantai (Km) & Kedalaman (Km) & Skala & Efek \\
\hline 1 & Dekat & Sangat Dalam & Tinggi & \\
\hline
\end{tabular}

Selanjutnya mencari efek yang ditimbulkan dari data testing dengan menggunakan Nä̈ve Bayes Classifeir

1. Menghitung Nilai $\mathrm{p}(\mathrm{XK} \mid \mathrm{H})$ tiap kelas

$\mathrm{P}($ Atribut 1 = "Dekat" $\mid$ Efek = "Tsunami")

$\mathrm{P}$ (Atribut $1=$ "Dekat" = 2/4 = 0.5)

P(Atribut $1=$ "Dekat" $\mid$ Efek = "Potensi Tsunami")

$\mathrm{P}($ Atribut $1=$ "Dekat" $=1 / 4=0.25)$

P(Atribut 1 = "Dekat" | Efek = "Tidak Berpotensi") 
$\mathrm{P}($ Atribut $1=$ "Dekat" $=0 / 7=0)$

$\mathrm{P}($ Atribut 2 = "Sangat Dalam" | Efek = "Tsunami")

$\mathrm{P}($ Atribut $2=$ "Sangat Dalam" $=1 / 4=0.25)$

$\mathrm{P}($ Atribut 2 = "Sangat Dalam" $\mid$ Efek = "Potensi Tsunami")

$\mathrm{P}($ Atribut $2=$ "Sangat Dalam" $=3 / 4=0.75)$

$\mathrm{P}$ (Atribut 2 = "Sangat Dalam" | Efek = "Tidak Berpotensi")

$\mathrm{P}($ Atribut $2=$ "Sangat Dalam" = 3/7 = 0.43)

$\mathrm{P}($ Atribut 3 = "Tinggi" | Efek = "Tsunami")

$\mathrm{P}($ Atribut $3=$ "Tinggi" $=3 / 4=0.75)$

$\mathrm{P}($ Atribut $3=$ "Tinggi" $\mid$ Efek $=$ "Potensi Tsunami")

$\mathrm{P}($ Atribut $3=$ "Tinggi" $=3 / 4=0.75$ )

$\mathrm{P}($ Atribut 3 = "Tinggi" $\mid$ Efek = "Tidak Berpotensi")

$\mathrm{P}($ Atribut $3=$ "Tinggi" $=0 / 7=0$ )

2. Menghitung Nilai $\mathrm{p}(\mathrm{X} \mid \mathrm{H})$ untuk tiap kelas label

$\mathrm{P}(\mathrm{X} \mid \mathrm{Efek}=$ "Tsunami" $)$

$=0.5^{*} 0.25^{*} 0.75=0.009375$

$\mathrm{P}(\mathrm{X} \mid$ Efek $=$ "Potensi Tsunami")

$=0.25 * 0.75 * 0.75=0.140625$

$\mathrm{P}(\mathrm{X} \mid \mathrm{Efek}=$ "Tidak Berpotensi")

$=0 * 0.43^{*} 0=0$

3. Menghitung Nilai $\mathrm{p}(\mathrm{X} \mid \mathrm{H}) * \mathrm{p}(\mathrm{H})$

$(\mathrm{P}(\mathrm{X} \mid$ Efek $=$ "Tsunami" $) \times \mathrm{P}($ Efek=Tsunami")

$=0.009375 * 4 / 15=0.009375 * 0.27=0.00253125$

$(\mathrm{P}(\mathrm{X} \mid \mathrm{Efek}=$ "Potensi Tsunami") $\mathrm{x}$ P(Efek=Potensi Tsunami")

$=0.140625 * 4 / 15=0.140625 * 0.27=0.03796875$

$(\mathrm{P}(\mathrm{X} \mid \mathrm{Efek}=$ "Tidak Berpotensi") $\times \mathrm{P}($ Efek=Tidak Berpotensi")

$=0 * 7 / 15=0 * 0.47=0$

4. Menentukan Kelas Dari Kasus

Berdasarkan perhitungan akhir dengan mengalikan nilai peluang dari kasus yang di angkat, dapat dilihat bahwa nilai P(X|Efek="Potensi Tsunami") lebih tinggi dari P(X|Efek="Tsunami") dan P(X|Efek="Tidak Berpotensi")

Tabel 7. Hasil Proses Klasifikasi

\begin{tabular}{|l|l|l|l|l|}
\hline No & $\begin{array}{l}\text { Jarak Dari Pantai } \\
\mathbf{( K m})\end{array}$ & $\begin{array}{l}\text { Kedalaman } \\
\mathbf{( K m )}\end{array}$ & Skala & Efek \\
\hline 1 & Dekat & Sangat Dalam & Tinggi & Potensi Tsunami \\
\hline
\end{tabular}

\section{KESIMPULAN}

Berdasarkan hasil dan pembahasan dapat ditarik kesimpulan bahwasaannya dengan menerapkan algoritma Nä̈ve Bayes Classifier (NBC) pada data gempa bumi terhadap potensi tsunami di Indonesia bisa mengetahui kemungkinan efek yang 
diakibatkan pada gempa bumi.Dengan data testing yang digunakan efek dihasilkan adalah Potensi Tsunami.

\section{DAFTAR PUSTAKA}

[1] E. Buulolo, N. Silalahi, Fadlina and R. Rahim, "C4.5 Algorithm To Predict the Impact of the," International Journal of Engineering Research \& Technology (IJERT), vol. 6, no. 2, pp.10-15, 2017.

[2] S. F. Rodiyansyah and E. Winarko, "Klasifikasi Posting Twitter Kemacetan Lalu Lintas Kota Bandung Menggunakan NaiveBayesian Classification," Indonesian Journal of Computing and Cybernetics System (IJCCS), vol. 6, no. 1, pp. 91-100, 2012.

[3] E. Prasetyo, Data Mining Konsep dan Aplikasi Menggunakan MATLAB, Yogyakarta: Andi, 2012.

[4] E. Prasetyo, Data Mining Mengolah Data Menjadi Informasi Menggunakan Matlab, Yogyakarta: Andi, 2014.

[5] D. Nofriansyah, Buku Algoritma Data Mining dan Pengujian, 2017.

[6] A. Jananto, "Algoritma Naive Bayes untuk Mencari Perkiraan Waktu Studi Mahasiswa," Jurnal Teknologi Informasi DINAMIK, vol. 18, no. 1, pp. 09-16, 2013.

[7] Sunarjo, M. T. Gunawan and S. Pribadi, Gempa Bumi Edisi Populer, Jakarta: Badan Meteorologi, Klimatologi dan Geofsika, 2012. 